\title{
Nature and Determinants of Educators' Attitudes toward Teaching Special Needs Learners in a School of Skills
}

\author{
Rowan Andre ${ }^{1}$ \\ Researcher, Department of Education, Western Cape, \\ South Africa \\ Moletsane Kekae Mokgadi ${ }^{2}$ \\ Professor, University of the Western Cape, South \\ Africa \\ CORRESPONDENCE \\ Rowan Andre \\ Psychology of Education, Department of Educational \\ Psychology, University of the Western Cape, Bellville, \\ Email: arowan777@gmail.com \\ Copyright: \\ (c) The Author(s) 2021. \\ Published by ERRCDF. This is an Open Access \\ article distributed under the terms of the Creative \\ Commons Attribution-NonCommercial- \\ NoDerivatives (CC BY-NC-ND 4.0) licence. \\ DOI: https://doi.org/ijspsy-2021.vol1.02.02
}

\begin{abstract}
This study explored the nature and determinants of educators' attitudes toward teaching learners with special needs in a rural school of skills that was formerly an ordinary mainstream school. The study adopted a qualitative Grounded Theory approach located within the framework of the constructivist epistemology. Eleven educators $(n=11)$ who were teaching both technical and academic subjects at the school of skills participated in the study. The semistructured interview was employed as the sole data collection instrument and the coding principles underlying the Constructivist Grounded Theory were used to analyse data. The findings of the study revealed that educators had a positive attitude toward teaching special needs education at the selected school and highlighted the novel factors determining the educators' attitudes such as both internal and external factors that motivated this positive attitude. The coping strategies identified by the educators replicated those reported in previous research. Palliative and direct coping actions, as well as an integration of these two were also reportedly employed by some participants. It was concluded that the group-based differentiation of the determinants of attitudes may be useful to influence educators' attitudes at
\end{abstract}

other special needs schools, or those undergoing a similar transitional process.

Keywords: Coping strategies, Determinants of attitude, Educational transformation, Educators' attitude, Inclusive education, school of skills, Special Needs Education.

\section{Introduction}

The development of inclusive policies internationally has stressed the importance of inclusive learning, thus incorporating learners with special needs in regular schools after a long period of discrimination and exclusion. For example, the Salamanca Statement considered that inclusion of special needs learners in regular schools should be the most effective strategy in combating discriminatory attitudes and creating inclusive communities (UNESCO, 1994). In South Africa, the White Paper Six was legislated to protect the education of all learners regardless of their learning barriers, language, culture, religion, or ethnicity (Department of Education, 2001). Therefore, this investigation was firstly motivated by previous research findings attesting to the fact that the educators' attitude could significantly determine the educational success of learners with special needs (Lindsay, 2007). Secondly, not enough investigation had been conducted to determine the attitudes of educators towards Special Needs Education, and more specifically in the context of a local school of skills.

In 2010, the school of skills designated for this investigation was reconstituted from a mainstream school to a school of skills (SoS). This school of skills also included an extra component, a junior and senior class catering to the educational needs of severely mentally and physically handicapped (SMH) children, but these did not form part of this study. Before its transformation, the school served the surrounding community of mainstream learners classified as ordinary mainstream learners without learning barriers of any serious kind for seventy-five years.

Considering the transformed status of the school, this investigation was interested in the anomalous nature of the school as most of the staff teaching at the former mainstream school remained part of the school of skills (SoS). Therefore, the reclassification of the school from mainstream education to one catering to learners' special needs precipitated interesting observations concerning the experiences of the teaching staff that remained at the school following its transformation. The focus of the investigation was on the observable attitudes resulting from 
the experiences of these educators as they grappled with the new challenges, particularly the changed learner profile at the newly classified special school or school of skills.

In the Western Cape Province of South Africa, where this study took place, schools serving learners with special education needs are referred to as LSEN schools by the Western Cape Education Department (WCED). In this regard, these LSEN schools cater to the needs of learners with physical disabilities, neurodevelopmental disorders such as autism, the deaf or visually impaired, and also include schools of skills (SoS). In this context, it is important to note that schools of skills enrol learners aged between 14 and 18 years who are experiencing barriers to learning because of cognitive, behavioural, and specific learning difficulties (dyslexia, dysgraphia, dyscalculia etc.) and do not progress at the same rate as their peers in the mainstream educational setting. These learners, however, do not seem to exhibit specific sensory, neurodevelopmental or physical disabilities but are perceived to require support in the form of an adapted curriculum. These schools are also defined by the South Africa National Association for Special Schools (SANASE) as catering to the needs of learners with mild intellectual disabilities (SANASE, 2001).

\section{Literature review}

\subsection{Attitude and educators' attitudes}

The conceptual definition of attitude adopted for this study was originally proposed by Eagly and Chaiken $(1993,1998)$, in the sense that attitude is seen as a psychological tendency that is expressed by evaluating a particular entity with some degree of favour or disfavour. According to Eagly and Chaiken (2007), the concept of attitude could further be divided into two classes, namely, positive or negative and neutral. Many international studies have been undertaken to explore the concept of teacher attitude and differential findings were noted (Alghazo \& Gaad, 2004; Avramidis \& Kalyva, 2007; Batsiou, Bebetsos, Panteli, \& Antoniou, 2008; Bussing, Gary, Leon, Garvan, \& Reid, 2002; Cook, 2001; De Bettencourt, 1999; Everington, Stevens, \& Winters, 1999; Glaubman \& Lifshitz, 2001; Kim, Park, \& Snell, 2005).

Some of the findings indicate that teachers held neutral views with regard to inclusive education (Kim et al., 2005; Opdal, Wormæs \& Habayeb, 2001). Batsiou, Bebetsos, Panteli, and Antoniou (2008) investigated the behaviour of teachers towards educating pupils with special needs in regular classrooms and found that teachers were neutral in their behavioural intentions, i.e. not overtly positive or negative in their attitude towards these pupils. Hammond and Lawrence (2003) investigated teachers' attitudes towards inclusive education and the results replicated the view on neutral attitudes. Similar studies confirmed the neutrality of teachers' attitudes towards educational inclusion (Avramidis \& Kalyva, 2007; Sari, 2007; Pearson, Eva, Ernest, \& Donna, 2003). Alghazo and Gaad (2004) also indicated that teachers had a neutral attitude towards the inclusion of pupils with special needs in mainstream education.

In contrast, other studies found that educators had negative attitudes towards inclusive education. For example, an investigation conducted by Everington, Stevens, and Winter (1999) found no strong positive attitudes exhibited by teachers towards teaching learners with special needs. Kalyva, Gojkovic, and Tsakiris (2007) investigated the attitudes of Serbian primary school teachers and reported that they held slightly negative attitudes towards the core perspectives of educational inclusivity (Kalyva, Gojkovic, \& Tsakiris, 2007). Jobling and Moni (2004) also found that most educators had a negative attitude towards the inclusion of learners with special needs in the mainstream education system. In South Africa Mdikana, Ntshangase, and Mayekiso (2007) noted that $35 \%$ of educators had a negative attitude towards inclusive education. Similar findings on negative attitudes were concluded by Gaad (2007) and Sari (2009). However, some scholars like Greene (2017) found both positive and negative attitudes for inclusionary teaching practices at schools in the USA. For this study, the two classes of attitudes, namely positive or negative and neutral, proposed by Eagly and Chaiken (1993), provided a conceptual framework for reviewing previous research and exploring teachers' attitudes towards teaching learners with special needs.

\subsection{Determinants of educators' attitude}


Research has shown several determinants of educators' attitudes toward inclusive education. Studies reported years of teaching experience as one of the determinants of educators' attitudes towards inclusive education, and revealed that clear differences existed in terms of attitudes between teachers with and without experience with inclusive education, as experienced teachers tend to have less positive attitudes than those with limited experience (Kalyva et al., 2007; Everington et al., 1999; Avramidis \& Kalyva, 2007). Various studies demonstrated that teachers with fewer years of teaching experience had significantly more positive attitudes towards the inclusion of pupils with special educational needs than their more experienced counterparts (Glaubman \& Lifshitz, 2001; Alghazo \& Gaad, 2004).

Training in Special Needs Education was identified as another significant determinant of educators' attitude towards inclusive education. Batsiou, Bebetsos, Panteli and Antoniou (2008) investigated the attitudes and intentions of Greek and Cypriot primary school teachers with regard to the inclusion of children with special educational needs (SENs) in mainstream schools, and the results showed that experience, knowledge, information and tertiary-level education could be regarded as positively influencing the attitudes and intentions of teachers with regard to teaching learners with Special Educational Needs in regular classrooms. Glaubman and Lifshitz (2001) also investigated the influence of in-service training on teachers' attitudes toward inclusion and found that the scores on the questionnaire that sought to determine the attitude of regular teachers increased significantly after a knowledge-based intervention. Comparatively, the findings reported by Kim et al. (2005) indicated that mainstream teachers who received written information through newsletters and weekly contact with special needs educators had a significantly more positive attitude towards the inclusion of pupils with special educational needs. Rose (2007) also investigated teachers' attitudes towards inclusion of learners with Special Education Needs and found that knowledge of teaching learners with special needs seemed to influence positive attitudes.

Gender differences have also been found to determine the attitude of teachers in mainstream education regarding inclusive education. A study by Alghazo and Gaad (2004) found significant gender-based differences between male and female teachers, with males reported to have had less positive attitudes towards inclusive education than their female counterparts. Similarly, Opdal, Wormæs, and Habayeb (2001) reported that female teachers were more supportive towards inclusion of learners with special needs than male teachers.

Studies also identified the type of learning disability as a significant determinant of educators' attitudes towards inclusive education (Cook, 2001; Glaubman \& Lifshitz, 2001). Previous research compared educators' attitudes towards pupils with mild and severe disabilities and the findings revealed that educators would be relieved by the exclusion of learners with learning disabilities, Attention Deficit/Hyperactivity Disorder, or behavioural problems from their class (Cook, 2001). Glaubman and Lifshitz (2001) also found that teacher attitudes were most negative towards the inclusion of pupils with learning disabilities, mild emotional problems, mild mental retardation, medium and severe emotional problems, and mental retardation. Ghanizadeh, Bahredar, and Moeini (2006) examined teacher attitudes towards the inclusion of children with AD/HD and hardly reported any positive attitudes. Alghazo and Gaad (2004) also noted that the attitude of educators was most negative towards learners with special educational needs, particularly those with disruptive or behavioural issues and $\mathrm{AD} / \mathrm{HD}$. The same study further reported that teachers were most negative about the inclusion of pupils with mental and behavioural difficulties and hearing impairment. Lifshitz et al. (2004) also found that teacher attitudes differed depending on the type of disability. The investigation further established that teachers were more likely to exhibit negative attitudes towards pupils with mental retardation and moderate or severe behavioural and emotional disorders (Lifshitz et al., 2004).

\subsection{Links between Inclusive Education and Special Needs Education}

Given the expertise and support that White Paper Six expects from teachers engaged in special education, this study hypothesized that the staff in Special Needs Education and special schools should exhibit a positive rather than negative attitude towards their teaching practice to effectively 
provide the support and transfer knowledge to educators in mainstream schools. A literature review was undertaken on the topic of teacher attitude in special needs education to provide a framework for this investigation, and a lack of available research was found regarding the attitudes of special needs teachers, especially those in the local South African context.

An extended pre-investigation review of the literature did however find a myriad of investigations undertaken to determine the attitudes of teachers in the mainstream education regarding the implementation of inclusive education for all learners including those with special educational needs (Petty \& Saddler, 1996; Engelbrecht, Green, Naicker, \& Engelbrecht, 1999; Hay, Smit, \& Paulsen, 2001; Swart, Engelbrecht, Eloff, \& Pettipher, 2002; Moberg, 2003). However, because of the lack of research data on the attitudes of teachers of Special Needs Education towards inclusive education and the provision of Special Needs Education it necessitated the need to use these research findings on the attitudes of mainstream educators toward inclusive education as a conceptual guideline for the current investigation. The rationale for this approach was that some teachers in mainstream inclusive schools' function partly in a context similar to that of the school of skills with regard to the inclusion and education of learners with special needs.

\section{Aim of the Study}

This study aimed to explore the nature and determinants of the attitude of educators toward teaching special needs learners in a rural school of skills recently converted from an ordinary mainstream school.

\section{Methodology}

\subsection{Research design}

This study adopted a qualitative Grounded Theory approach placed within the constructivist epistemology. The Grounded Theory was perceived as the most appropriate approach for its systematic but flexible method of collecting and analysing qualitative data to construct theories directly grounded in the collected data. The constructivist thread of the Grounded Theory was chosen to enable the study to focus on the attitudes of the participants toward teaching at a school of skills, thus allowing an exploration of the nature of their attitudes. The Constructivist Grounded Theory was also regarded as fit for this purpose since it fosters openness and an empathetic understanding of participants' meanings, actions, and contexts, with the potential to transform their teaching practice.

\subsection{Participants}

The participants involved educators who had transitioned from a mainstream school to one offering Special Needs Education, and during the initial interviews with them, three educator profiles could be identified at the school; the first group had previous experience in imparting Special Needs Education, the second group comprised educators with no experience of Special Needs Education, and finally, there was one educator who was sourced from the private sector and had no teaching experience. Before the interviews were conducted, all eleven of the participants granted written consent, and were also notified in writing of their freedom to withdraw their participation at any time during the study without repercussion. A group of four educators termed transition educators, as indicated in Table 1, were interviewed at the outset of the study. These consisted of those teachers who were employed at the erstwhile mainstream school prior to its conversion into a school of skills. Of these four educators, two, that is, one male and one female, taught mainstream subjects such as Afrikaans and Accounting. The other two educators, also a male and a female, taught technical subjects, Woodwork and Hospitality Studies.

Table 1: Transition educators

\begin{tabular}{lllll}
\hline Educators & Age & Gender & Subject and Year Group Taugl Teaching Experience in SNE \\
\hline Transition educator 1 & 47 & Male & Woodwork Year 1-4 & 3 years (from 2012) \\
Transition educator 2 & 45 & Female & Office Practice Year 1-4 & 3 years (from 2012) \\
Transition educator 3 & 55 & Female & Hospitality Studies Year 1-4 & 3 years (from 2012)
\end{tabular}


The only experience of teaching learners with special needs these educators had at the time of the interview was acquired since the transformation of the school at the beginning of 2011. In terms of learner profiles, it should be acknowledged that the two educators teaching technical subjects previously taught learners who coped academically at mainstream levels, Grades 9 to 12, before the school was converted into a school of skills, and were now teaching learners who barely coped at Grade 4 level.

The second group of educators, which was identified from the responses of the transition educators, was a group termed SNE experienced educators, owing to their previous experience in teaching Special Needs Education, as noted in Table 2.

Table 2: SNE Experienced educators

\begin{tabular}{|c|c|c|c|c|c|}
\hline Educators & Age & Gender & $\begin{array}{l}\text { Subject and Year } \\
\text { Taught }\end{array}$ & $\begin{array}{l}\text { Grc Teaching } \\
\text { SNE }\end{array}$ & Experience \\
\hline SNE Experienced educator 1 & 52 & Male & English Year 1-4 & 14 years & \\
\hline SNE Experienced educator 2 & 62 & Female & Upholstery Year 1-4 & 18 years & \\
\hline
\end{tabular}

The third group was also identified and classified as novice educators as presented in Table 3 . This group consisted exclusively of female educators who had no experience in Special Needs Education. The first educator in this group previously taught at a Further Education and Training (FET) college and also owned a hair salon. The second and third educators had just finished their studies and assumed their first teaching positions at the school of skills. The fourth educator in this group had taught at a mainstream school for two years before assuming her current position at the school of skills.

Table 3: Novice educators

\begin{tabular}{lllll}
\hline Educators & Age & Gender & Subject and Year Group Taught & $\begin{array}{l}\text { Teaching Experience } \\
\text { SNE }\end{array}$ \\
\hline Novice educator 1 & 33 & Female & Hairdressing Year 1-4 & 1 year (since 2014) \\
Novice educator 2 & 21 & Female & Afrikaans Year 1-4 & 1 year (since 2014) \\
Novice educator 3 & 20 & Female & Afrikaans Year 1-4 & 1 year (since 2014) \\
Novice educator 4 & 24 & Female & Life Orientation Year 1-4 & 1 year (since 2014) \\
\hline
\end{tabular}

A single educator, who was identified following a conversation with the Headmaster, presented an educational anomaly since he was previously employed in the automotive mechanical sector with no prior formal teaching experience or qualification. He was therefore labelled as private sector/no formal education experience as shown in Table 4.

Table 4: Private sector/No formal education experience

\begin{tabular}{|l|l|l|l|l|}
\hline Educator & Age & Gender & Subject and Year Group & SNE Teaching experience \\
\hline Educator 1 & 53 & Male & Mechanics Year 1-4 & 1 year (since 2013) \\
\hline
\end{tabular}

\subsection{Instrument}

This study employed semi-structured intensive interviews to collect data. According to Charmaz (2006), an intensive interview is characterised by conversational qualities and can produce rich data which can be analysed to produce tacit meanings. She further notes that the participants' conversations with the interviewer and the way they talk about the phenomena under 
investigation will provide valuable insights into more tacit values and assumptions (Charmaz, 2006). The choice of this instrument was further motivated by the desire to elicit rich data that might have been lost because some teachers seemed verbally stronger in their convictions than others, especially when interviewed in a group context. The interviews lasted approximately one hour since the intensity of the interviews could only be enabled by a lengthy interview lasting about an hour according to Charmaz (2006). The interviews were conducted over a period of three months at the school of skills and in the classrooms of the eleven participating educators. The participants held both technical and academic teaching posts at the school of skills. The cordial and relaxed atmosphere created during the interviews was enhanced by the fact that the participants were acquainted with the researcher, which helped them to be completely at ease when they were invited to talk openly about their practice and attitudes. Owing to their familiarity with the researcher, those participants who agreed to participate were also comfortable with being recorded and appeared to freely share their thoughts and feelings with the researcher.

\subsection{Data Analysis}

The coding principles underlying the Constructivist Grounded Theory, as proposed by Charmaz (2006), were used in this investigation. The first step in the process of initial data coding is the lineby-line data coding practice. In vivo codes were used to link the units of meaning, keeping them as close to the actual data as possible. Coding was also completed approximately within sixteen hours after the interviews had been conducted when participants' responses were still fresh in the memory of the researcher. Focused coding was also conducted to bring the fractured data together, thus developing categories and sub-categories (Charmaz, 2006). The initial codes generated from all the interviews with individual participants were subsequently collated for the identification of the salient codes which would be used for all the data. At this stage, codes were then clustered according to the seemingly salient themes emerging from the interviews with the participants. When examining a cluster of codes representing participants' responses to specific questions, the researcher had to construct a focused code which was representative of all the participants' responses. This strategy involved continuously refining and re-labelling the focused codes to ensure that it was inclusive of all the initial codes that constituted the responses to questions. The final integration of the categories was done using an approach like the axial coding process proposed by Strauss and Corbin (1998).

\subsection{Ethical Considerations}

Before data collection, the researcher obtained ethical clearance from the University of the Western Cape and permission to research schools from the Western Cape Education Department. Permission was also granted from the school principal to access the selected school. Individual consent forms were signed by participants confirming their participation in the study. The participants were selected according to predetermined criteria. The researcher assured that participants' identities and responses were extremely confidential, and pseudo-names were used to ensure the participants' confidentiality. Participants were informed about their right to withdraw from participating at any given time, should they feel uncomfortable.

\section{Results and discussion}

\subsection{Nature of educator attitude towards teaching in a special needs school}

All the participants in this study were asked to answer questions that interrogated the nature of their attitude towards imparting Special Needs Education at the school of skills. The findings show that all the participants had a positive attitude toward teaching at this school, regardless of normal day-to-day frustrations with learners on the one hand, and the general education system on the other. Subsequent to an analysis of the reported frustrations, it emerged that these did not significantly influence the positivity of educators' attitude. The participants confirmed that these frustrations were part of their normal practice and shared the following views about their frustrations:

"The fact is that children are referred to a school like this for the wrong reasons, for example, disciplinary reasons" (Male Transition Educator 1) 
Int. j. sud. psychol.

"I do not like the politics occurring in the school and I try to refrain from such sensitive issues" (Female Novice Educator 2).

"I had some trouble at the beginning of the year to get my sources together in terms of the curriculum since there are no real prescribed textbooks" (Female Novice Educator 3).

\subsection{Determinants of educators' attitudes}

\subsubsection{Educators' positive attitude}

This study revealed a perceived strong positive attitude exhibited by participants. Remarks shared in support of this perception were:

"I feel very positive about working with them to try to change their lives" (Female Novice Educator 4).

"I feel very positive about this kind of education I am imparting. I actually think it is an honour to teach in inclusive education" (Female Novice Educator 2).

"I feel that this is a stunning opportunity that came my way. I have always helped apprentices in my own salon and I always felt that I would like to help kids" (Female Novice Educator 1).

In relation to the literature reviewed for this study, which reported mixed results on the positivity or negativity of educators' attitudes toward teaching special needs (Alghazo \& Gaad, 2004; Avramidis \& Kalyva, 2007; Batsiou, Bebetsos, Panteli, \& Antoniou, 2008; Glaubman \& Lifshitz, 2001; Lifshitz, Glaubman, \& Issawi, 2004; Kim, Park, \& Snell, 2005), the current study in contrast found only an overwhelmingly positive attitude toward teaching special needs learners among all the participants.

\subsubsection{Training in special needs education}

The findings of previous studies suggested that training in Special Needs Education could be considered a determinant of educators' attitudes toward teaching learners with special needs. In this regard, previous research concluded that more training in Special Needs Education would usually result in educators acquiring a more positive attitude. The current study, which investigated the determinants of educators' attitude, produced results similar to those reported by previous studies; however, a perceived lack of training did not appear to play a significant role in the context of educators involved in the special needs education at the school of skills, despite this lack of opportunity to engage in professional development. In support of this view, the participants remarked the following when asked about the amount of training received to teach special needs learners:

"There is none, except the day when I went to the Westcoast School and received some old materials from a teacher teaching there. We had a total of 3 courses from Ruben and the Department (of Education) about conflict handling and so on" (Female Transition Educator 2).

"We got none of that training, except for a few professional development courses offered by the Department of Education" (Male Transition Educator 1).

Previous research concluded that the positivity of educators' attitude usually increased with more training and experience (Avramidis and Kalyva, 2007; Ghanizadeh, Bahredar, \& Moeini, 2006; Carroll, Forlin \& Jobling, 2003), the findings were partly corroborated by this study, but in the sense that despite the lack of the opportunity for professional development and enough preparation for the teaching of learners with special needs participants however still shared a positive attitude. This conclusion was based on the participants' high level of attitudinal positivity despite the stated perception that they lacked exposure to enough professional development opportunities and training, or any experience in Special Needs Education.

\subsection{Types of learning barriers}

Previous studies found that types of learning barriers could act as a determinant of educators' attitudes. In this regard, the participants mentioned that this determinant depended on the context 
and that teacher attitudes were rather based on the attitudes of the learners than their learning barriers. In support of this view, the participants remarked:

"Learning barriers are caused by those that are disrespectful and do not accept authority. They try to make it as difficult as possible for the educator thus making it unpleasant for the whole class" (Female Transition Educator 2).

"I do not want to struggle with behaviour problems and a negative attitude" (Male Transition Educator 1).

"I do not think I would classify learners as such. I would rather keep on making repeated efforts with a learner depending on his or her attitude rather than the classification criterion..." (Female SNE Experienced Educator 2).

The reviewed literature revealed that types of learning barriers played a significant role in instigating the negativity of educators' attitude towards teaching learners with special needs (Cook, 2007; Glaubman \& Lifshitz, 2001; Ghanizadeh, Bahredar \& Moeini, 2006). Regarding the type of learning barrier, the participants in this study, however, reported that they mostly did not use this determinant to determine how to respond to and manage a learner. Instead, the earlier arrangement suggested by the different groupings of educators turned out to be significant when the transition group perceived learners' attitude as the main criterion determining the amount of effort they are willing to make rather than a specific learning barrier. The novice, private sector, and the experienced in special needs groups, in turn, reported that they would rather focus on integrating the full inclusion of learners with approaches aligned to notions such as curriculum delivery differentiation and learner management strategies.

\subsection{Gender-based factors}

Contrary to the findings discussed in the literature review (Alghazo \& Gaad, 2004; Boyle, Topping \& Jindal-Snape, 2013), this study demonstrated that gender could not be considered a significant determinant of educators' attitudes towards teaching learners with special needs at the School of Skills. The participants stated that they regarded some traits such as the advantage of a stronger personality type as more significant than gender. Regarding the possibility of a gender advantage in the teaching of learners with special needs at the school of skills, only one male participant reported that male educators seemed to have an advantage over female colleagues in this type of school. Remarks in support of this perception were:

"I think it has much more to do with your way of teaching and handling kids than your gender" (Female SNE Experienced Educator 2).

"I think being a man does not present significant benefits since I believe it is all about how the educator handles their class. I think it is the educator's attitude that makes the class what it is" (Female SNE Experienced Educator 1).

"Sometimes, it is more difficult for the ladies because the kids test the borders first" (Male Transition Educator 2).

An alternative theory was also proposed by the male participant in the group of educators experienced in teaching learners with special educational needs. According to him issues of authority among the younger male educators and their desire to oversee the classroom, usually resulted in a clash with behaviourally challenging learners sharing similar authority issues.

\subsection{Motivation: either internal or external base}

The responses to the two questions that probed the participating educators to share their perceptions of the determinants of their attitude were analysed and the results indicated that the motivation of educators was characterised by either an internal or external base. An internal base for motivation was defined as the educators' perceptions that they made a difference in the learners' lives, experienced significant job satisfaction, and played a meaningful role in the lives of their learners. The remarks shared in support of this perception were: 
"I find it quite pleasurable since I was trained as a practical Woodwork teacher. I can bond with these kids at another level, and there is considerably less pressure on marks and performance" (Male Transition Educator $3)$.

"I now have more empathy than I had three years ago. I was used to teaching a Matric class, and suddenly, I had kids that did not know a from $b$. They are typing much better now, and that gives me job satisfaction" (Female Transition Educator 2).

Responses representing the defined external base for motivation that stimulates a positive attitude, in turn, were characterised by educators' convictions of the general gratefulness of the learners, coupled with the lowered pressure for high performance in terms of assessment outcomes in comparison with expectations in mainstream education. Remarks shared in support of this conviction were:

"With me being close to retirement, I feel quite comfortable and happy because of the reduced workload compared to the mainstream" (Female SNE Experienced Educator 1).

"There is less pressure compared to the mainstream with all the marking and the curriculum. At this stage in my life with my own family, this is good for me (Female Transition Educator 4).

Further notions of the external base for motivation were educators' understanding of the learner's reason for exhibiting challenging behaviour, a favourable outdoor work environment, a deeply personal motivation, the academic growth of the learner, making a difference in their lives, and finally caring for the well-being of these learners were also cited as motivating a positive attitude. The remarks in support of this view were:

"The biggest reason for my positive attitude is the kids and the fact that you can make a difference to at least one kid" (Female Novice Educator 2).

"One of the biggest reasons is the difference that I make in the lives of the kids as well as at the community level" (Female Novice Educator 1).

When the literature study is considered, regarding the previously defined internal and external bases for the motivation of the teacher's positive attitude, it should be pointed out that this new classification is conceptual and was identified through the findings of the study. For this reason it may not be sensible at this point to compare the findings of the literature study to this novel classification of internal or external bases for the positive attitude of the teachers toward teaching at this type of school.

\subsection{Coping strategies employed by special needs educators to manage stress}

This study found that the coping strategies used by the participants at the School of Skills corresponded to previous research, in the sense that a direct-action type of approach to coping strategies was reported by both the male and female participants in the group of educators experienced in teaching learners with special needs. Both male educators in the transition group also reported the same strategy. In support of this position they noted:

"Very thorough planning is important to me, and this helps a lot. You have to plan individual tasks for every child's specific lag" (Male SNE Experienced Educator 1).

"What is important to note in this kind of school is that you cannot come to class unprepared. You must plan very thoroughly and keep these kids always busy (Female SNE Experienced Educator 2).

"I had my strategy all planned out before I began teaching at the new school, which helped a lot" (Male SNE Experienced Educator 1).

This exploration of the coping mechanisms employed by the teachers showed that they used approaches like those identified in the literature review by using either a palliative or direct-action type of approach. An alternative classification was also added based on the responses of three of the four educators in the novice group when they reported the use of a mix of both palliative and direct action. They pointed out the following : 
"I think that planning is very important, and I usually try to do everything for the next day. My dad also advises me to focus on the positive aspects. If something bad happens here at the school, I leave it here and go and chill at home" (Female Novice Educator 4).

"One of my coping mechanisms involve taking an hour or so after leaving school, and then go to my own salon to work" (Female Novice Educator 3).

"In this sense, it is then definitely important to plan well as a coping mechanism. You cannot even seem not to have everything well-planned, since they see this and then take chances. I also tend to avoid people after school for an hour or so just to reboot" (Female Novice Educator 1).

When taking into account the different coping strategies employed by teachers the findings of this study supported those of the literature, in the sense that teachers used the direct-action type of approach as described by Dunham (1984), Kyriacou (1980), and Dewe, Guest and Williams (1979). Further agreement with the literature was that teachers also employed the other palliative type of approach to coping with stress as noted by Cockburn (1996) and Johnstone (1989). The study also produced some new knowledge in the sense that some teachers used both of the strategies (palliative and Direct-action) mentioned in the literature simultaneously.

\section{Conclusion}

The educators' attitude toward teaching learners with special educational needs at the school of skills was found to be notably positive, notwithstanding some normalised day-to-day frustrations with the learners and the education system. The study has proved that their positive attitude plays an important role in the effective functioning of the school of skills since a departmental wholeschool evaluation process classified the school as highly functional by all Western Cape Department of Education standards. The most significant determinants of the educators' attitudes seem to be based either on internal cognitive processes underpinned by feelings that they truly make a difference and play a significant role in the lives of the learners, or on a relatively objective observation of the educational benefits experienced by the learners as a result of their teaching efforts. The four defined groups of educators at the school of skills also presented different professional profiles and experiences while teaching Special Needs Education and subsequently, they seemed to present significantly different determinants of their attitude. Since the proposed strategy of infusion of knowledge from special needs educators to mainstream educators has been highlighted by White Paper Six (2001), the findings presented by this investigation should be applied to Special Needs Education and also the future transformational process of inclusive mainstream schools. The possible implication of the findings, concerning educators' group-based differentiation of determinants of attitude, is that it may be used as a strategy to foster a positive attitude among teachers, especially those at other special schools, or those undergoing a similar transitional process. Another significant implication may be that the management of special needs institutions should develop an awareness of the differing professional needs of educators based on the determinants of their attitude. Precisely, this study contributes to the effective functioning of institutions offering special needs education and it envisions support for the creation of a functional and fully inclusive mainstream education system. Thus, educators' attitude must be understood and carefully managed to realise the goals of the White Paper Six on education in South Africa.

\section{References}

Alghazo, E.M. \& Gaad, N. (2004). General education teachers in the United Arab Emirates and their acceptance of the inclusion of students with disabilities. British Journal of Special Education, 31, 94-9.

Avramidis, E., \&Kalyva, E. (2007). The influence of teaching experience and professional development on Greek teachers' attitudes towards inclusion. European Journal of Special Needs Education, 22, 367-89.

Balboni, G., \&Pedrabissi, L. (2000). Attitudes of Italian teachers and parents toward school inclusion of students with mental retardation: The role of experience. Education $\mathcal{E}$ Training in Mental Retardation $\mathcal{E}$ Developmental Disabilities, 35, 148-59.

Batsiou, S., Bebetsos, E., Panteli, P., \& Antoniou, P. (2008). Attitudes and intention of Greek and Cypriot primary education teachers towards teaching pupils with special educational needs in mainstream schools. International Journal of Inclusive Education, 12, 201-19. 
Boyle,C., Topping, K., \& Jindal-Snape, D. (2013). Teachers' attitude towards inclusion in high schools. Teachers and teaching. 19(5), 527-542

Bussing, R., Gary, F., Leon, C., Garvan, C., \& Reid, R. (2002). General classroom teachers' information and perceptions of attention deficit hyperactivity disorder. Behavioral Disorders, 27, 327-38.

Carroll, A., Forlin, C., Jobling, A. (2003). The Impact of Teacher Training in Special Education on the Attitudes of Australian Preservice General Educators towards People with Disabilities. Teacher Education Quarterly, 30(3), 65-79.

Charmaz, K. (2005). "Grounded Theory in the 21st Century: Applications for Advancing Social Justice Studies". In N Denzin \& Y Lincoln, (Eds.). The Sage Handbook of Qualitative Research. (3rd ed., pp. 507-535). Thousand Oaks, CA: Sage.

Charmaz, K. (2006). Constructing grounded Theory: A practical guide through qualitative analysis. London: Sage Publications Limited.

Cook, B. (2001). A comparison of teachers' attitudes toward their included students with mild and severe disabilities. Journal of Special Education, 34, 203-13.

De Bettencourt, L. U. (1999). General educators' attitudes toward students with mild disabilities and their use of instructional strategies: Implications for training. Remedial and Special Education, 20, 27-35.

Department of Education. (2001). White Paper 6 on Inclusive Education and Training. Pretoria: Government Printers.

Department of Education. (2001). White Paper 6 on Inclusive Education and Training. Pretoria: Government Printers.

Eagly, A. H., \&Chaiken, S. (2007). The advantages of an inclusive definition of attitude. Social cognition, 25(5), $582-602$.

Eagly, A.H., \&Chaiken, S. (1993). The psychology of attitudes. Fort Worth: Harcourt Brace College

Everington, C., Stevens, B., \& Winters, V. (1999). Teachers' attitudes, felt competence, and need of support for implementation of inclusive educational programs. Psychological Reports, 85, 331-8.

Gaad, E., \& Khan, L. (2007). Primary Mainstream Teachers' Attitudes Towards Inclusion of Students With Special Educational Needs In The Private Sector: A Perspective From Dubai. International Journal of Special Education, 22(2),95-109.

Ghanizadeh, A., Bahredar, M.J., \& Moeini, S.R. (2006). Knowledge and attitudes towards attention deficit hyperactivity disorder among elementary school teachers. Patient Education and Counseling, 63, 84-8.

Glaubman, R., \&Lifshitz, H. (2001). Ultra-orthodox Jewish teachers' self-efficacy and willingness for inclusion of pupils with special needs. European Journal of Special Needs Education, 16, 207-23.

Jobling, A., \& Moni, K. (2004). 'I never imagined I'd have to teach these children': Providing authentic learning experiences for secondary pre-service teachers in teaching students with special needs. Asia-Pacific Journal of Teacher Education, 32, March 2004.

Kalyva, E., Gojkovic, D., \& Tsakiris, V. (2007). Serbian teachers' attitudes towards inclusion. International Journal of Special Education, 22, 31-36.

Kim, J., Park, E., \& Snell, M. (2005) . Impact of information and weekly contact on attitudes of Korean general educators and nondisabled students regarding peers with disabilities. International Journal of Development and Education, 59(4), 379-392.

Leyser, Y., \& Kirk, R. (2004). Evaluating inclusion: An examination of parent views and factors influencing their perspectives. International Journal of Disability Development and Education, 51, 271-85.

Lindsay, G. (2007). Educational psychology and the effectiveness of inclusive education/ mainstreaming. British Journal of Educational Psychology, 77, 1-24.

Mdikana, A., Ntshangase, S., \&Mayekiso, T. (2007). Pre-Service Educators' Attitudes towards Inclusive Education. International Journal of Special Education, (22) No1.Retardation, 43, 401-15.

Opdal, L., Wormnæs, S., \&Habayeb, A. (2001). Teachers' opinions about inclusion: A pilot study in a Palestinian context. International Journal of Disability, Development and Education, 48, 143-62.

Pearson, V., Eva, L., Ernest, C., \& Donna, W. (2003). A heart to learn and care? Teachers' responses toward special needs children in mainstream schools in Hong Kong. Disability and Society, 18, 489-508.

Petty, R. E. (2018). Attitudes and persuasion: Classic and contemporary approaches. Routledge.

Rose, R. (2001). Primary school teacher perceptions of the conditions required to include pupils with special educational needs. Educational Review, 53, 147-56.

SANASE. (2001). Interprovincial coordination committee for intellectually mildly disabled learners. South Africa: SANASE Committee.

Sari, H. (2007). The influence of an in-service teacher training (INSET) programme on attitudes towards inclusion by regular classroom teachers who teach deaf students in primary schools in Turkey. Deafness and Education International, 9, 131-46. 
Int. j. sud. psychol.

Strauss, A., \& Corbin, J. (1998). Basics of qualitative research: Techniques and procedures for developing grounded Theory (2nd ed.). Newbury Park: Sage.

UNESCO. (1994). The Salamanca Statement and Framework for Action on Special Needs Education. Paris: UNESCO. 